Volume 1

Issue 3 - Cardio-Oncology

Article 3

\title{
8-13-2014
}

\section{Diagnosis of Chemotherapy-Induced Cardiotoxicity}

\author{
Fausto Pizzino \\ Giampiero Vizzari \\ Charles A. Bomzer \\ Rubina Qamar \\ Scipione Carerj \\ Concetta Zito \\ Bijoy K. Khandheria
}

Follow this and additional works at: https://aah.org/jpcrr

Part of the Cardiology Commons, and the Oncology Commons

\section{Recommended Citation}

Pizzino F, Vizzari G, Bomzer CA, Qamar R, Carerj S, Zito C, Khandheria BK. Diagnosis of chemotherapyinduced cardiotoxicity. J Patient Cent Res Rev. 2014;1:121-127. doi: 10.17294/2330-0698.1025

Published quarterly by Midwest-based health system Advocate Aurora Health and indexed in PubMed Central, the Journal of Patient-Centered Research and Reviews (JPCRR) is an open access, peer-reviewed medical journal focused on disseminating scholarly works devoted to improving patient-centered care practices, health outcomes, and the patient experience. 


\section{Diagnosis of Chemotherapy-Induced Cardiotoxicity}

Fausto Pizzino, MD, ${ }^{1}$ Giampiero Vizzari, MD,${ }^{1}$ Charles A. Bomzer, MD, ${ }^{2}$ Rubina Qamar, MD, ${ }^{2}$

Scipione Carerj, MD, PhD, ${ }^{1}$ Concetta Zito, MD, ${ }^{1}$ Bijoy K. Khandheria, MD ${ }^{3}$

${ }^{1}$ Clinical and Experimental Department of Medicine and Pharmacology, University of Messina, Messina, Italy

${ }^{2}$ Department of Medical Oncology/Hematology, Aurora Advanced Healthcare, Milwaukee, WI

${ }^{3}$ Aurora Cardiovascular Services, Aurora Sinai/Aurora St. Luke's Medical Centers, University of Wisconsin School of

Medicine and Public Health, Milwaukee, WI

\section{Abstract}

Cardiotoxicity is a rising issue connected to use of chemotherapy and radiotherapy in the treatment of neoplastic diseases. Early diagnosis during follow-up is of paramount importance, and careful surveillance is recommended. Evaluation of left ventricular ejection fraction by echocardiography and nuclear medicine techniques is widely used in clinical practice; however, their sensitivity in detecting early cardiac damage is low. New instruments like speckle-tracking imaging, cardiac magnetic resonance and cardiac circulating biomarkers are available to clinicians to best evaluate the onset and progression of cardiotoxic effects, improving the therapeutic management and final outcome for the patient. (J Patient-Centered Res Rev. 2014;1:121-127.)

\section{Keywords}

cardiotoxicity, chemotherapy side effects, imaging method, cardiac biomarkers

\section{Introduction}

The introduction of chemotherapy significantly improved the outcome of cancer patients and represents a fundamental element in treatment of several tumors. However, chemotherapy is associated with negative side effects that greatly limit its use. Cardiotoxicity is one of the most relevant issues connected to implementation of some classes of chemotherapeutic agents because of its negative effect on prognosis and quality of life. ${ }^{1}$ Radiotherapy directed to the chest alone or in association with chemotherapy is an additional cause of cardiac damage in oncologic patients. Progressive impairment of systolic function leading to overt heart failure is the most common manifestation of chemotherapy-induced cardiomyopathy (CICM); however, other complications like hypertension, acute coronary syndrome, arrhythmias and thrombosis have been

Correspondence: Bijoy K. Khandheria, MD, Aurora Cardiovascular Services, 2801 W. Kinnickinnic River Parkway, \#840, Milwaukee, WI, 53215, Phone: 414-649-3909, Fax: 414-649-3551,

Email: publishing22@aurora.org described. CICM is usually characterized by a long stage of subclinical myocardial dysfunction that is not detectable by conventional diagnostic methods but which is important for patient prognosis. The early diagnosis and adequate evaluation of the cardiotoxic effects of chemotherapeutic drugs are of paramount importance for clinicians to set the best therapeutic management.

\section{Main Chemotherapeutic Drugs Associated With Cardiotoxicity} Anthracyclines

Doxorubicin, epirubicin and daunorubicin are chemotherapeutic drugs strongly associated with cardiotoxicity, which usually occurs within 1 year of treatment at an incidence of about $2 \% .^{2}$ They are widely used in the treatment of breast cancer, lung cancer, hematological malignancies and sarcoma. The cardiotoxic effect is related to the cumulative dose of the drug, especially for doxorubicin, for which $550 \mathrm{mg} / \mathrm{m}^{2}$ is considered the maximal accepted threshold. ${ }^{3}$

\section{Trastuzumab}

A monoclonal antibody used in the treatment of breast cancer that is positive for the expression of the ErbB2 growth factor receptor, ${ }^{4}$ trastuzumab generates an increase in cardiotoxicity incidence when combined with anthracyclines. The cardiotoxic effect is frequent, occurring in up to $28 \%$ of patients. $^{5}$

\section{Tyrosine-Kinase Inhibitors}

This category includes several drugs that share a similar mechanism of action that consists of inhibiting different tyrosine kinases, enzymes involved in the signal transduction process. Imatinib, dasatinib and nilotinib inhibit ABL-kinase and are used for treatment of some forms of leukemia; cardiotoxic effect occurs in $1 \%$ of treated patients. ${ }^{6}$ Sunitinib and sorafenib were designed to inhibit tyrosine kinases involved in both tumor proliferation and angiogenesis; $3-11 \%$ of patients develop cardiotoxicity. ${ }^{7}$ 


\section{Antibody Therapies}

Hypertension occurs in about $50 \%$ of bevacizumab-treated patients; conversely, cetuximab and rituximab are associated with severe orthostatic hypotension. ${ }^{8}$

\section{Antimetabolites}

Capecitabine and 5-fluorouracil are associated with myocardial ischemia in $1.2 \%$ to $18 \%$ of treated patients. ${ }^{9}$

\section{Alkylating Agents}

Cisplatin can induce hypertension. Myocardial ischemia, thrombosis, acute coronary syndrome and symptomatic left ventricular dysfunction also have been reported, mostly in older patients. Cyclophosphamide is widely used in many hematologic malignancies. Myocarditis can occur, with an incidence in adults estimated at $7-25 \%$ at doses $>150 \mathrm{mg} / \mathrm{kg}{ }^{8}$

\section{Taxanes}

Docetaxel and paclitaxel induce cardiotoxicity in $2.3 \%$ to $8 \%$ of patients. They are mainly used in the treatment of patients with breast, lung or ovarian cancer. ${ }^{10}$
A list describing the main features of chemotherapeutic medications associated with cardiovascular side effects is reported in Table 1.

\section{Cardiovascular Complications of Radiotherapy}

Radiotherapy is presently a widely used anticancer treatment. High-dose irradiation focused on the thorax is mainly used in the context of adjuvant treatment after surgery for breast cancer, as adjuvant or selected therapy of lung and esophageal cancer, and as complementary treatment for lymphoma. ${ }^{11}$ However, radiosensitivity of the heart is one of the most critical radiation dose-limiting factors. The outcome of long-term cancer survivors can be affected by radiationinduced heart disease, related to the total cumulative dose of radiotherapy (number of treatments and dose of irradiation). ${ }^{12}$ Irradiation of the heart can lead to a wide range of clinical effects, including pericarditis, coronary artery disease and myocardial infarction, valvular heart disease, rhythm anomalies and nonischemic myocardial damage (restrictive cardiomyopathy). Estimated incidence of radiation-induced heart damage is $10-30 \%$ at $5-10$ years after treatment;

Table 1. Chemotherapeutic medications associated with cardiovascular side effects

\begin{tabular}{|c|c|c|c|c|c|}
\hline Drug & $\begin{array}{l}\text { Antineoplastic } \\
\text { mechanism }\end{array}$ & Malignancy & $\begin{array}{l}\text { Cardiotoxic } \\
\text { effect }\end{array}$ & $\begin{array}{l}\text { Incidence of } \\
\text { cardiotoxicity }\end{array}$ & $\begin{array}{l}\text { Mechanism of } \\
\text { cardiotoxicity }\end{array}$ \\
\hline $\begin{array}{l}\text { anthracyclines (cumulative dose): } \\
\text { doxorubicin (>500 mg/m²); } \\
\text { liposomial doxorubicin }\left(>900 \mathrm{mg} / \mathrm{m}^{2}\right) \text {; } \\
\text { epirubicin }\left(>720 \mathrm{mg} / \mathrm{m}^{2}\right) ; \\
\text { mitoxantrone }\left(>120 \mathrm{mg} / \mathrm{m}^{2}\right) \text {; } \\
\left.\text { idarubicin (>90 } \mathrm{mg} / \mathrm{m}^{2}\right)\end{array}$ & $\begin{array}{l}\text { - tumor cell DNA } \\
\text { damage }\end{array}$ & $\begin{array}{l}\text { - hematologic } \\
\text { - breast } \\
\text { - multiple myeloma } \\
\text { - lung } \\
\text { - sarcoma }\end{array}$ & - heart failure & - $2 \%$ & $\begin{array}{l}\text { - production of free } \\
\text { radicals }\end{array}$ \\
\hline trastuzumab & $\begin{array}{l}\text { - inhibition of } \\
\text { ErbB2 }\end{array}$ & - breast & - heart failure & • 1\%-28\% & $\begin{array}{l}\text { - mitochondrial } \\
\text { damage }\end{array}$ \\
\hline imatinib, dasatinib, nilotinib & $\begin{array}{l}\text { - inhibitors of } \\
\text { ABL-kinase }\end{array}$ & $\begin{array}{l}\text { - BCR/ABL-positive } \\
\text { leukemia }\end{array}$ & - heart failure & $\cdot 1.7 \%$ & $\begin{array}{l}\text { - inhibition of ABL } \\
\text { tyrosine kinase on } \\
\text { cardiomyocytes }\end{array}$ \\
\hline sunitinib, sorafenib & $\begin{array}{l}\text { - inhibition of } \\
\text { tyrosine kinases } \\
\text { involved in } \\
\text { angiogenesis } \\
\text { and proliferation }\end{array}$ & $\begin{array}{l}\text { - kidney } \\
\text { - gastrointestinal } \\
\text { stromal tumors } \\
\text { - hepatocarcinoma }\end{array}$ & $\begin{array}{l}\text { - heart failure } \\
\text { - acute coronary } \\
\text { syndromes } \\
\text { - hypertension }\end{array}$ & - 3\%-8\% & $\begin{array}{l}\text { - inhibition of } \\
\text { tyrosine kinases } \\
\text { involved in } \\
\text { cardiomyocytes } \\
\text { survival } \\
\end{array}$ \\
\hline bevacizumab & $\begin{array}{l}\text { vascular- } \\
\text { endothelial } \\
\text { growth factor } \\
\text { inhibitor }\end{array}$ & $\begin{array}{l}\text { - colon } \\
\text { - lung } \\
\text { - glioblastoma }\end{array}$ & - hypertension & - $50 \%$ & • unknown \\
\hline 5-fluorouracil & $\begin{array}{l}\text { - alteration of } \\
\text { DNA structure }\end{array}$ & $\begin{array}{l}\text { - gastrointestinal } \\
\text { tumors } \\
\text { - breast }\end{array}$ & $\begin{array}{l}\text { - myocardial } \\
\text { ischemia }\end{array}$ & - $1.2 \%-18 \%$ & $\begin{array}{l}\text { - vasospasm } \\
\text { - autoimmune } \\
\text { phenomena } \\
\text { - myocarditis }\end{array}$ \\
\hline cisplatin & $\begin{array}{l}\text { - alteration of } \\
\text { DNA structure }\end{array}$ & $\begin{array}{l}\text { - lung } \\
\text { - stomach } \\
\text { - bladder } \\
\text { - ovary } \\
\text { - testicle } \\
\end{array}$ & $\begin{array}{l}\text { - hypertension } \\
\text { - heart failure }\end{array}$ & - unknown & - oxidative stress \\
\hline cyclophosphamide & $\begin{array}{l}\text { - alkylation of } \\
\text { guanine }\end{array}$ & $\begin{array}{l}\text { - Iymphoma } \\
\text { - leukemia }\end{array}$ & - myocarditis & - $7 \%-25 \%$ & • unknown \\
\hline taxanes (paclitaxel, docetaxel) & $\begin{array}{l}\text { - disruption of } \\
\text { microtubule } \\
\text { function }\end{array}$ & $\begin{array}{l}\text { - lung } \\
\text { - ovary } \\
\text { - breast } \\
\text { - prostate }\end{array}$ & - heart failure & - $2.3 \%-8 \%$ & $\begin{array}{l}\text { - lipid peroxidation } \\
\text { - direct cytotoxic } \\
\text { damage }\end{array}$ \\
\hline
\end{tabular}


in these patients, cardiovascular disease is the first nonmalignant cause of death. ${ }^{13}$ Radiation effects appear to be accelerated by the conjunction of common cardiovascular risk factors and to increase the risk of cardiotoxicity of some chemotherapeutic agents, such as anthracyclines.

\section{Manifestation of Cardiotoxicity and Main Risk Factors}

The progressive decline of left ventricular systolic and diastolic function is the most common manifestation of CICM. A variable long subclinical stage precedes the onset of heart failure symptoms like dyspnea, asthenia and peripheral edema. Cardiomyocyte damage secondary to chemotherapy is classified in two groups. Type I chemotherapy-related myocardial dysfunction is usually secondary to oxidative stress (typically anthracycline-induced) and results in cardiomyocyte death; it is an irreversible, dose-dependent process and leads to ultrastructural alterations identifiable at myocardial biopsy. Type II chemotherapy-related myocardial dysfunction (typically trastuzumab-induced) is caused by cardiomyocyte impairment rather than cell death; it is not dose-related and may be reversible. ${ }^{10}$ Myocardial ischemia presenting with T-wave changes, chest pain, acute coronary syndrome and myocardial infarction is another possible cardiotoxic effect of chemotherapeutic agents like 5-fluorouracil. ${ }^{14}$ Hypertension, hypotension and thromboembolic events are other cardiovascular complications of cancer treatment. ${ }^{8,15}$ It appears clear that the incidence of cardiotoxicity is related to the presence of risk factors: young or old age, female gender, prior mediastinal radiation therapy, hypertension, and combined chemotherapy and presence of underlying cardiac disease. $^{2}$ The finding of any of these in a patient undergoing chemotherapy should encourage more aggressive follow-up.

\section{Diagnosis and Monitoring of Cardiotoxicity}

Although endomyocardial biopsy remains the most sensitive and specific method to assess cardiotoxicity by describing the microscopic structural alterations of myocardial tissue, its use is strongly limited because of the high invasiveness of the procedure. ${ }^{16}$ Electrocardiographic (ECG) alterations may occur during treatment with cancer drugs; these include decreased QRS voltage and ST-T wave changes. However, the most common and relevant finding consists in QT corrected (QTc) interval prolongation. ${ }^{17}$ QTc measures the total duration of the electric depolarization and repolarization of myocardium; its prolongation is associated to increased risk of ventricular arrhythmias, particularly torsades de pointes, and sudden death. The underlying mechanism is mediated by the interaction of chemotherapeutic drugs with the human ether-a-go-go-related gene product, a protein subunit of a potassium ion channel (hERG K+). ${ }^{18}$ Although elongation of QTc occurring during chemotherapy treatment is relatively frequent $(14 \%$ in a series of 525 patients enrolled in phase I clinical trial) ${ }^{19}$ and ECG monitoring is strictly recommended in the follow-up of chemotherapy-treated patients, the association between this electric disorder and major cardiac events has not yet been proved in this set of patients. Imaging methods such as echocardiography are more often used to evaluate CICM in clinical practice. Left ventricular ejection fraction (LVEF) evaluated by two-dimensional echocardiography is the standard parameter for assessment of the cardiotoxic effect of chemotherapy. The Cardiac Review and Evaluation Committee (CREC) defined that the diagnosis of CICM can be established when at least one of the following elements is present: 1) cardiomyopathy characterized by a decrease in cardiac LVEF that was either global or more severe in the septum; 2) symptoms of congestive heart failure; 3) associated signs of congestive heart failure, including but not limited to S3 gallop, tachycardia, or both; and 4) decline in LVEF of at least 5\% to less than 55\% with accompanying signs or symptoms of congestive heart failure, or a decline in LVEF of at least $10 \%$ to below 55\% without accompanying signs or symptoms. ${ }^{5}$ Echocardiography also can provide important data on diastolic function that is usually altered early on in patients who develop CICM..$^{20}$ Although widely used, LVEF measured by two-dimensional echocardiography is calculated using some geometrical assumptions, which influences the reproducibility of the metric. LVEF evaluation by three-dimensional echocardiography is derived by a volumetric analysis of the left ventricle and is free from any geometrical assumption, resulting in a more accurate and reproducible measurement. ${ }^{21}$ Stress echocardiography was proposed as a method to identify early systolic dysfunction due to chemotherapy. However, data are very poor and the results derived from small studies have been conflicting. ${ }^{22}$ An alternative imaging method used to monitor LVEF in chemotherapy-treated patients is represented by $99 \mathrm{mTC}$ multigated radionuclide angiography (MUGA), a nuclear imaging method able to visualize the cardiac blood pool by $\gamma$-camera with ECG-triggered acquisitions. The final result provides a highly reproducible and precise quantification of left ventricular volumes and dyssynchrony that does not derive from geometrical assumption. ${ }^{23}$ Although LVEF evaluation using two- or three-dimensional echocardiography or MUGA is widely used in clinical practice, it is unable to detect the earliest myocardial impairment or predict which patients have an increased risk for developing CICM. New imaging techniques and biomarker evaluation are emerging methods developed to overcome the limitation of LVEF as the sole analysis. 


\section{New Insights in the Early Detection of the Myocardial Damage \\ Speckle-Tracking Imaging}

Myocardial contraction consists of a complex spatial deformation depending on the particular anatomical array of the muscular fibers. The main components of deformation are represented by longitudinal, circumferential and radial deformation. Twist, untwist and torsion are additional components depending on the different orientation of the fibers between apex and base of the heart. Speckle tracking analyzes the myocardial deformation on two- and threedimensional images by tracking natural acoustic reflections and interference patterns, called "speckle," within an ultrasonic window. The analyzer software is able to provide the percentage variation of distance (deformation) between speckles within a predefined region of interest, obtaining a value defined as "strain." The velocity of the deformation is defined as "strain rate" (Figure 1). The evaluation of strain and strain rate in patients receiving chemotherapy has been evaluated in several studies, which demonstrated a concrete advantage in early identification of left ventricular dysfunction and predicting future decline of LVEF. ${ }^{24,25}$

\section{Cardiac Magnetic Resonance Imaging}

Cardiac magnetic resonance (CMR) represents the criterion standard method in the evaluation of cardiac volumes, mass and function. ${ }^{22,25}$ Moreover, "tissue characterization" performed by CMR reveals alterations like fibrosis, edema and inflammation. In the early stage of CICM, CMR is able
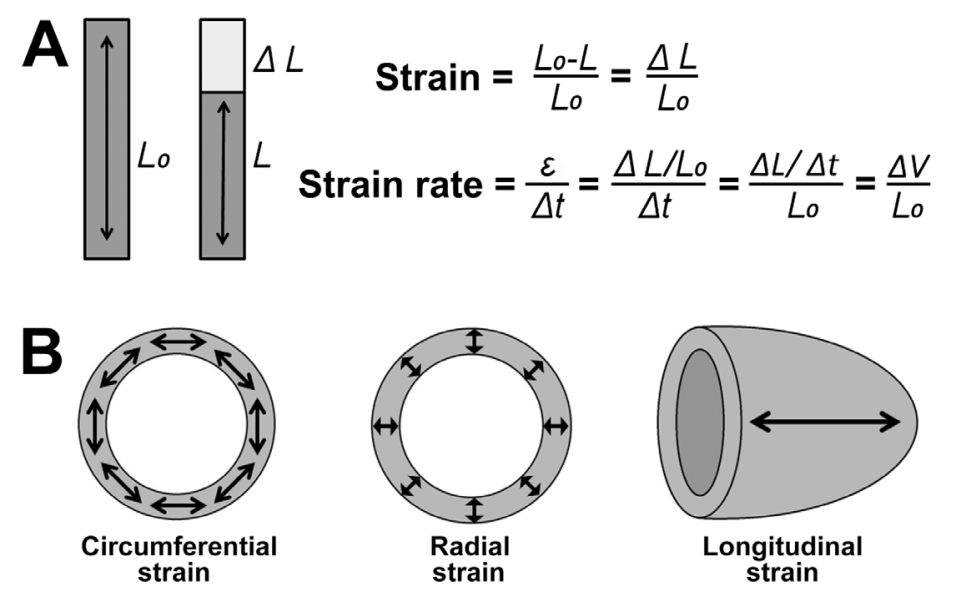

Figure 1. Definition of strain and strain rate. A: Strain $(\varepsilon)$ is defined as the difference of the initial and the final distance between two points divided by the initial distance. Strain rate derives from the ratio between the velocity variation and the initial distance between two points. B: Graphical representation of the main deformation components of the left ventricle. $L_{0}$, initial distance; $L$, final distance; $\Delta L$, distance variation; $\Delta t$, time variation; $\Delta V$, velocity variation. to detect myocardial edema using T2-weighted sequences and myocardial inflammation by $\mathrm{T} 1$-weighted fast-spin echo sequences after administration of gadolinium. ${ }^{26}$ Delayed sequence acquisition after contrast is used to investigate late gadolinium enhancement, which detects tissue presenting a slow contrast wash-out, usually consisting of scar or fibrosis. Early alterations of late gadolinium enhancement have been described in chemotherapy-treated patients and are predictive of development of CICM and decline of LVEF. ${ }^{26}$ In studies including adults who survived childhood malignancies, CMR demonstrated individuated late effects of cardiotoxicity: the reduction of the cardiac mass in comparison to safe controls is an indicator of late cardiotoxicity and is associated with increased risk of cardiac events. ${ }^{26}$ Moreover, the accurate definition of volumes and function provided by CMR demonstrated a higher sensibility than echocardiography in detecting minimal alteration of LVEF with elevated reproducibility. ${ }^{27}$

\section{Circulating Biomarkers}

Injury of cardiomyocytes causes the release of substances into the blood flow that can be used as biomarkers of subclinical myocardial damage. Ultrasensitive troponin I is the most reliable marker as detecting the level of the concentration of ultrasensitive troponin I after the treatment is predictive of development of cardiotoxicity $(\mathrm{P}=0.020$; hazard ratio 1.38 per standard deviation). ${ }^{28}$ The same study also identified an increase of myeloperoxidase as an indicator of cardiotoxicity, and the coexistence of the two markers was associated with the highest risk of future myocardial dysfunction. Contrasting opinions have been reported about N-terminal pro-B-type natriuretic peptide (NT-proBNP). It did not demonstrate a predictive value for development of cardiotoxicity in the study carried out by Ky et al. ${ }^{28}$ However, other studies showed early variation of NT-proBNP levels can be used to identify patients at risk of cardiotoxicity. ${ }^{29,30}$ It is clear that larger studies are needed to confirm the potential promise of cardiac biomarkers in the identification of subclinical cardiotoxicity induced by chemotherapy and to provide reliable reference ranges.

\section{Cardiotoxicity Monitoring}

The systematic and integrative use of these new methods represents the future approach of clinicians to evaluate cardiotoxicity. Although endomyocardial biopsy remains the most sensitive and specific method to diagnose cardiac damage, its invasiveness limits its use to the few cases in which cardiac dysfunction is not clearly associated with chemotherapy treatment and should not be included as a screening method. LVEF remains the central parameter in the diagnosis and monitoring of cardiac function in chemotherapy-treated 
patients. However, the majority of authors demonstrated that the drop of myocardial systolic function revealed by this parameter is a late phenomenon in the pathophysiological mechanism of cardiotoxicity and that its evaluation alone substantially reduces the window for prevention. ${ }^{31}$

Data derived from three-dimensional echocardiography are more reproducible and accurate than two-dimensional echocardiography and should be preferred, if available. MUGA is the most used alternative to echocardiography (particularly when a bad acoustic window is present), and its sensitivity is comparable to three-dimensional echocardiography; ${ }^{23}$ however, MUGA is an old technique, born when CMR was an experimental instrument. It is less accurate in patients with arrhythmias; moreover, its use as a screening method significantly increases the radiation burden for the patient. The use of three-dimensional echocardiography and MUGA improves the accuracy and the interobserver variability of the measurement but does not outweigh the limitation inherent to the evaluation of LVEF. $^{32}$ Speckle-tracking echocardiography revealed good sensitivity in detecting early myocardial impairment, and analysis of global longitudinal strain should be performed during follow-up, integrating the information derived from LVEF. A decrease in global longitudinal strain is associated with long-term reduction of LVEF (in a recent systematic review, Thavendiranathan et al. reported that a reduction of $10-15 \%$ in global longitudinal strain is the most useful parameter in predicting a drop in LVEF or onset of heart failure symptoms ${ }^{33}$ ); nevertheless, its most important limitation is represented by the lack of large controlled studies providing reliable and well-established thresholds. CMR is the most accurate method for diagnosing alteration of left ventricular systolic function and allows detection of early tissue composition changes that can reflect early manifestation of cardiotoxicity. Unfortunately, CMR's high cost and low availability limit its wide implementation as a first-line screening instrument.

The usage of cardiac circulating biomarkers is an additional emerging method for early evaluation of cardiac function during and after chemotherapy, and the evaluation of ultrasensitive troponin I should be considered in patients at high risk to develop cardiotoxicity. The timing of dosage and thresholds are not yet well-established in literature. The guidelines of the European Society of Medical Oncology introduced the importance of new imaging techniques and of circulating biomarkers in the early diagnosis of cardiotoxicity, moreover, they suggested that a greater drop in LVEF is needed to establish diagnosis of cardiotoxicity (to $50 \%$ instead of the $55 \%$ previously stated by the CREC). ${ }^{34}$ Table 2 summarizes the strengths and limitations of the different methods involved in the evaluation of chemotherapyinduced cardiotoxicity.

Table 2. Strengths and limitations of the different methods used for diagnosis of cardiotoxicity

\begin{tabular}{|c|c|c|}
\hline Method & Strengths & Limitations \\
\hline Electrocardiogram & $\begin{array}{l}\text { - availability } \\
\text { - low cost } \\
\text { - repeatability }\end{array}$ & - poor sensitivity and specificity \\
\hline $\begin{array}{l}\text { Two-dimensional echocardiogram } \\
\text { (ejection fraction) }\end{array}$ & $\begin{array}{l}\text { - availability } \\
\text { - repeatability }\end{array}$ & $\begin{array}{l}\text { - unable to detect early dysfunction } \\
\text { - inter- and intraoperator variability } \\
\text { - dependency from geometrical assumptions }\end{array}$ \\
\hline $\begin{array}{l}\text { Three-dimensional echocardiogram } \\
\text { (ejection fraction) }\end{array}$ & $\begin{array}{l}\text { - low inter- and intraoperator variability } \\
\text { - independence from geometrical assumptions } \\
\text { - high reproducibility } \\
\text { - repeatability }\end{array}$ & $\begin{array}{l}\text { - unable to detect early dysfunction } \\
\text { - not available in all echo-labs }\end{array}$ \\
\hline $\begin{array}{l}\text { Multigated radionuclide angiography } \\
\text { (MUGA) }\end{array}$ & $\begin{array}{l}\text { - low inter- and intraoperator variability } \\
\text { - independence from geometrical assumptions } \\
\text { - high reproducibility } \\
\text { - repeatability }\end{array}$ & $\begin{array}{l}\text { - unable to detect early dysfunction } \\
\text { - radiation exposure } \\
\text { - low repeatability }\end{array}$ \\
\hline Speckle-tracking imaging & $\begin{array}{l}\text { - able to detect early systolic dysfunction } \\
\text { - repeatability } \\
\text { - independence from angle }\end{array}$ & $\begin{array}{l}\text { - not available in all echo-labs } \\
\text { - absence of well-established thresholds } \\
\text { - time-consuming } \\
\text { - low sensibility in patients with suboptimal } \\
\text { echocardiographic window }\end{array}$ \\
\hline Cardiac magnetic resonance & $\begin{array}{l}\text { - able to detect early systolic dysfunction } \\
\text { - highly reliable measure of volumes and mass } \\
\text { - very high reproducibility } \\
\text { - independence from geometrical assumptions } \\
\text { - tissue characterization } \\
\text { - no radiation exposure }\end{array}$ & $\begin{array}{l}\text { - elevated cost } \\
\text { - low availability } \\
\text { - not suitable for patients with metallic } \\
\text { devices }\end{array}$ \\
\hline Circulating biomarkers & - high sensitiveness & $\begin{array}{l}\text { - data derived only from studies on } \\
\text { anthracyclines }\end{array}$ \\
\hline
\end{tabular}


Figure 2 proposes a potential screening algorithm including classic and new techniques for monitoring the cardiovascular side effects of chemotherapy. Baseline evaluation should include biomarker assay and echocardiography evaluation

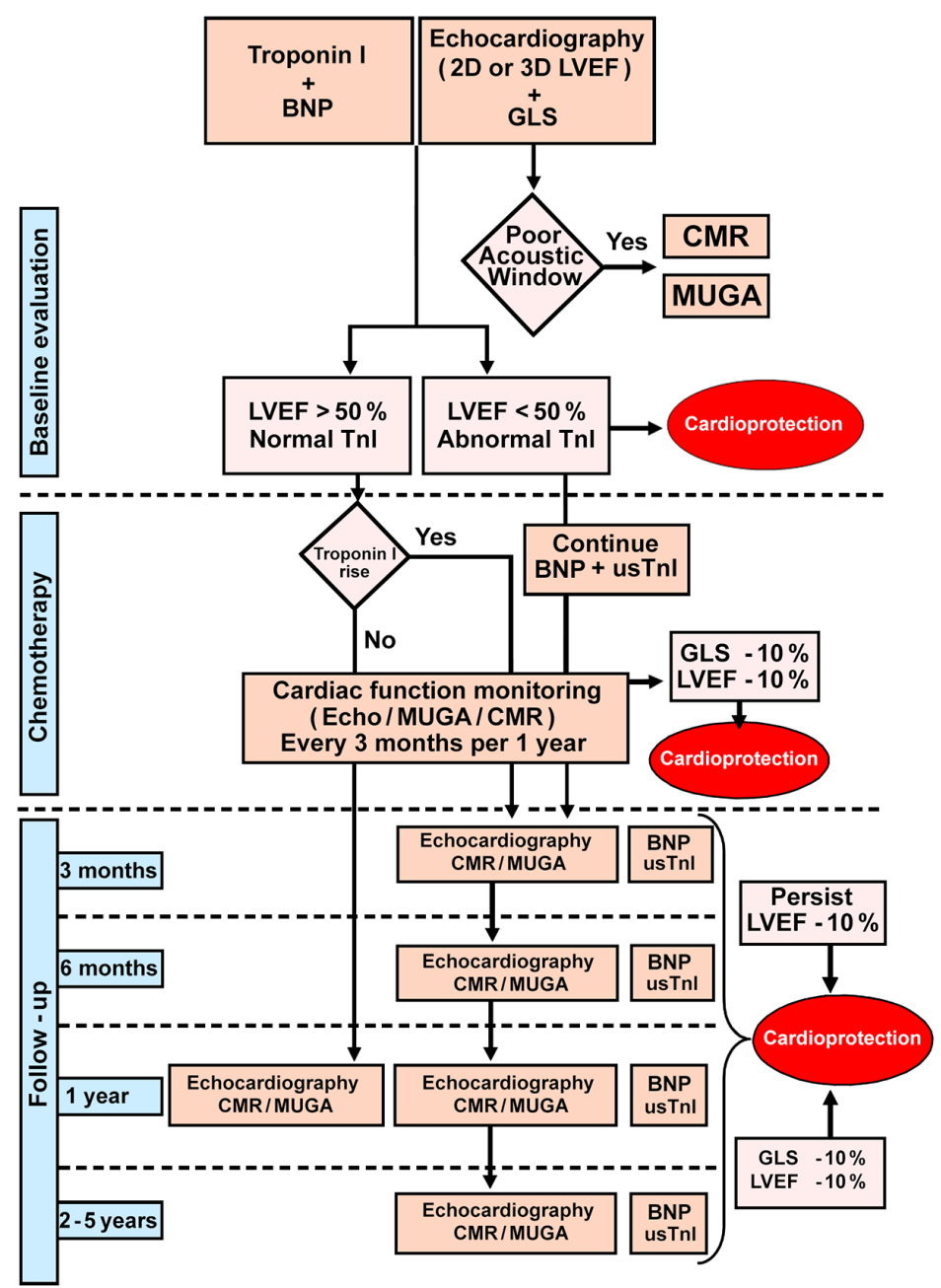

Figure 2. Flow chart for diagnosis of cardiotoxicity in chemotherapy-treated patients. Baseline evaluation includes biomarker assay and computing of left ventricular ejection fraction (LVEF) and global longitudinal strain (GLS). LVEF derived by three-dimensional (3D) echocardiography is more accurate and reproducible and therefore preferred; if the acoustic window is poor, cardiac magnetic resonance (CMR) or multigated radionuclide angiography (MUGA) are alternative methods. Patients presenting with normal LVEF and troponin I (Tnl) at baseline should be evaluated every 3 months during chemotherapy. If TnI increase does not occur during chemotherapy, the subsequent follow-up should be scheduled 1 year after the end of treatment. If baseline LVEF or Tnl are abnormal, a cardioprotection protocol is needed and a more intensive follow-up should be established with evaluation at 3 months, 6 months and 1 year after the end of treatment and every 6 months for 2-5 years. At every control, a drop of $10 \%$ of LVEF (below $50 \%$ ) or GLS is considered a manifestation of cardiotoxicity and should be treated with a cardioprotective protocol. BNP, B-type natriuretic peptide; usTnl, ultrasensitive troponin I. including global longitudinal strain; in a patient with bad acoustic window, CMR and MUGA are alternative options. During chemotherapy, assessment of troponin I is recommended after each cycle and evaluation of cardiac function should be performed every 3 months. If the baseline evaluation is normal and troponin I does not increase during chemotherapy, the timing for the subsequent follow-up control should be scheduled 1 year after the end of treatment. If an increase in troponin I occurs during chemotherapy, or the baseline evaluation is abnormal, a cardioprotection protocol should be started and a more intensive follow-up is needed with re-evaluation at 3 months, 6 months and 1 year and every 6 months for 2-5 years. A more aggressive cardioprotection protocol should be considered if alteration of biomarkers and/or LVEF or global longitudinal strain persists.

\section{Conclusion}

In the last decades, the development of a wide number of chemotherapeutic agents has permitted a substantial improvement of survival among cancer patients. Cardiotoxicity represents a rising problem affecting chemotherapy-treated patients. Although anthracyclines and herceptin are the drugs more frequently associated with cardiotoxicity, many other pharmaceutical classes have demonstrated cardiovascular side effects. Despite using left ventricular ejection fraction to evaluate cardiotoxic effect as recommended by the guidelines, it is widely accepted that this method is not sensitive in detecting early myocardial impairment, reducing the window for prevention and negatively influencing prognosis. The use of new techniques like deformation analysis, cardiac magnetic resonance and dosage of cardiac biomarkers demonstrated more sensitivity in detecting early cardiotoxicity, improving prognosis and quality of life of cancer patients. However, the fragmentary data derive from relatively small studies, thus larger controlled trials are needed to clearly define thresholds and screening protocols. Finally, we want to emphasize the importance of the close collaboration between cardiologists and oncologists for the correct management of chemotherapy-treated patients.

\section{Acknowledgments}

The authors gratefully acknowledge Susan Nord and Jennifer Pfaff of Aurora Cardiovascular Services for the editorial preparation of the manuscript and Brian J. Miller and Brian Schurrer of Aurora Sinai Medical Center for help with the figures.

\section{Conflicts of Interest}

Dr. Bomzer owns stock in Merck Inc. and Pfizer Inc. None of the other authors have any conflicts of interest relative to this submission. 


\section{References}

1. Yeh ET, Bickford CL. Cardiovascular complications of cancer therapy: incidence, pathogenesis, diagnosis, and management. J Am Coll Cardiol. 2009;53:2231-47.

2. Volkova M, Russell R 3rd. Anthracycline cardiotoxicity: prevalence, pathogenesis and treatment. Curr Cardiol Rev. 2011;7:214-20.

3. Von Hoff DD, Layard MW, Basa P, et al. Risk factors for doxorubicininduced congestive heart failure. Ann Intern Med. 1979;91:710-7.

4. Slamon DJ, Leyland-Jones B, Shak S, et al. Use of chemotherapy plus a monoclonal antibody against HER2 for metastatic breast cancer that overexpresses HER2. N Engl J Med. 2001;344:783-92.

5. Seidman A, Hudis C, Pierri MK, et al. Cardiac dysfunction in the trastuzumab clinical trials experience. J Clin Oncol. 2002;20:1215-21.

6. Verweij J, Casali PG, Zalcberg J, et al. Progression-free survival in gastrointestinal stromal tumours with high-dose imatinib: randomised trial. Lancet. 2004;364:1127-34.

7. Garcia-Alvarez A, Garcia-Albeniz X, Esteve J, Rovira M, Bosch X. Cardiotoxicity of tyrosine-kinase-targeting drugs. Cardiovasc Hematol Agents Med Chem. 2010;8:11-21.

8. Monsuez JJ, Charniot JC, Vignat N, Artigou JY. Cardiac side-effects of cancer chemotherapy. Int J Cardiol. 2010;144:3-15.

9. Fradley MG, Barrett CD, Clark JR, Francis SA. Ventricular fibrillation cardiac arrest due to 5-fluorouracil cardiotoxicity. Tex Heart Inst J. 2013;40:472-6.

10. Todaro MC, Oreto L, Qamar R, Paterick TE, Carerj S, Khandheria BK. Cardioncology: state of the heart. Int J Cardiol. 2013;168:680-7.

11. Lancellotti P, Nkomo VT, Badano LP, et al. Expert consensus for multi-modality imaging evaluation of cardiovascular complications of radiotherapy in adults: a report from the European Association of Cardiovascular Imaging and the American Society of Echocardiography. J Am Soc Echocardiogr. 2013;26:1013-32.

12. Darby SC, Cutter DJ, Boerma M, et al. Radiation-related heart disease: current knowledge and future prospects. Int J Radiat Oncol Biol Phys. 2010;76:656-65.

13. Carver JR, Shapiro CL, Ng A, et al. American Society of Clinical Oncology clinical evidence review on the ongoing care of adult cancer survivors: cardiac and pulmonary late effects. J Clin Oncol. 2007;25:3991-4008.

14. de Forni M, Malet-Martino MC, Jaillais P, et al. Cardiotoxicity of high-dose continuous infusion fluorouracil: a prospective clinical study. J Clin Oncol. 1992;10:1795-801.

15. Seng S, Liu Z, Chiu SK, et al. Risk of venous thromboembolism in patients with cancer treated with Cisplatin: a systematic review and meta-analysis. J Clin Oncol. 2012;30:4416-26.

16. Meinardi MT, van der Graaf WT, van Veldhuisen DJ, Gietema JA, de Vries EG, Sleijfer DT. Detection of anthracycline-induced cardiotoxicity. Cancer Treat Rev. 1999;25:237-47.

17. Bagnes C, Panchuk PN, Recondo G. Antineoplastic chemotherapy induced QTc prolongation. Curr Drug Saf. 2010;5:93-6.

18. Trinkley KE, Page RL 2nd, Lien H, Yamanouye K, Tisdale JE. QT interval prolongation and the risk of torsades de pointes: essentials for clinicians. Curr Med Res Opin. 2013;29:1719-26.

19. Naing A, Veasey-Rodrigues H, Hong DS, et al. Electrocardiograms (ECGs) in phase I anticancer drug development: the MD Anderson Cancer Center experience with 8518 ECGs. Ann Oncol. 2012;23:2960-3.

20. Di Lisi D, Bonura F, Macaione F, et al. Chemotherapy-induced cardiotoxicity: role of the tissue Doppler in the early diagnosis of left ventricular dysfunction. Anticancer Drugs. 2011;22:468-72.
21. Thavendiranathan P, Grant AD, Negishi T, Plana JC, Popović ZB, Marwick TH. Reproducibility of echocardiographic techniques for sequential assessment of left ventricular ejection fraction and volumes: application to patients undergoing cancer chemotherapy. J Am Coll Cardiol. 2013;61:77-84.

22. Kerkhove D, Fontaine C, Droogmans S, et al. How to monitor cardiac toxicity of chemotherapy: time is muscle! Heart. 2014;100:1208-17.

23. de Geus-Oei LF, Mavinkurve-Groothuis AM, Bellersen L, et al. Scintigraphic techniques for early detection of cancer treatmentinduced cardiotoxicity. J Nucl Med Technol. 2013;41:170-81.

24. Jurcut R, Wildiers H, Ganame J, et al. Strain rate imaging detects early cardiac effects of pegylated liposomal Doxorubicin as adjuvant therapy in elderly patients with breast cancer. JAm Soc Echocardiogr. 2008;21:1283-9.

25. Stoodley PW, Richards DA, Boyd A, et al. Left ventricular systolic function in HER2/neu negative breast cancer patients treated with anthracycline chemotherapy: a comparative analysis of left ventricular ejection fraction and myocardial strain imaging over 12 months. Eur J Cancer. 2013;49:3396-403.

26. Fallah-Rad N, Lytwyn M, Fang T, Kirkpatrick I, Jassal DS. Delayed contrast enhancement cardiac magnetic resonance imaging in trastuzumab induced cardiomyopathy. J Cardiovasc Magn Reson. 2008;10:5.

27. Armstrong GT, Plana JC, Zhang N, et al. Screening adult survivors of childhood cancer for cardiomyopathy: comparison of echocardiography and cardiac magnetic resonance imaging. J Clin Oncol. 2012;30:2876-84.

28. Ky B, Putt M, Sawaya H, et al. Early increases in multiple biomarkers predict subsequent cardiotoxicity in patients with breast cancer treated with doxorubicin, taxanes, and trastuzumab. J Am Coll Cardiol. 2014;63:809-16.

29. Feola M, Garrone O, Occelli M, et al. Cardiotoxicity after anthracycline chemotherapy in breast carcinoma: effects on left ventricular ejection fraction, troponin I and brain natriuretic peptide. Int J Cardiol. 2011;148:194-8.

30. Yildirim A, Tunaoglu FS, Kambur K, Pinarli FG. The utility of NTproBNP and various echocardiographic methods in the determination of doxorubicin induced subclinical late cardiotoxicity. Kardiol Pol. 2013;71:40-6.

31. DeCara JM. Early detection of chemotherapy-related left ventricular dysfunction. Curr Cardiol Rep. 2012;14:334-41.

32. Walker J, Bhullar N, Fallah-Rad N, et al. Role of three-dimensional echocardiography in breast cancer: comparison with two-dimensional echocardiography, multiple-gated acquisition scans, and cardiac magnetic resonance imaging. J Clin Oncol. 2010;28:3429-36.

33. Thavendiranathan P, Poulin F, Lim KD, Plana JC, Woo A, Marwick TH. Use of myocardial strain imaging by echocardiography for the early detection of cardiotoxicity in patients during and after cancer chemotherapy: a systematic review. $\mathrm{J}$ Am Coll Cardiol. 2014;63:2751-68.

34. Curigliano G, Cardinale D, Suter T, et al. Cardiovascular toxicity induced by chemotherapy, targeted agents and radiotherapy: ESMO Clinical Practice Guidelines. Ann Oncol. 2012;23 Suppl 7:vii155-66.

(C) 2014 Aurora Health Care, Inc. 